\title{
Activity patterns by two colour morphs of the vulnerable guiña, Leopardus guigna (Molina 1782), in temperate forests of southern Chile
}

\author{
Patrones de actividad de dos morfos de coloración de la vulnerable güiña, Leopardus \\ guigna (Molina, 1872), en bosques templados del sur de Chile
}

\author{
Felipe Hernández $^{1 *}$, Nicolás Gálvez ${ }^{1,2}$, Alessandro Gimona $^{3}$, Jerry Laker ${ }^{1}$ \& Cristián Bonacic ${ }^{1}$ \\ ${ }^{1}$ Fauna Australis Wildlife Laboratory, School of Agriculture and Forestry Sciences, Pontificia Universidad Católica \\ de Chile, Santiago, Chile \\ ${ }^{2}$ Pontificia Universidad Católica de Chile, Department of Natural Sciences, Villarrica Campus, Centre for Local \\ Development (CEDEL), Villarrica, Araucanía, Chile \\ ${ }^{3}$ The James Hutton Institute, Aberdeen, Scotland \\ *E-mail: fhernandeu@uc.cl
}

\begin{abstract}
Here we provide the first analysis of activity patterns exhibited by spotted and melanistic colour morphs of the vulnerable guiña Leopardus guigna, in a forest landscape of southern Chile. Camera traps showed guiñas were mainly active at night ( $64 \%$ of photos). Melanistic guiñas were more nocturnal ( $82 \%$ of photos) than the more common spotted cats $(57 \%)$. Spotted guiñas were more active on cloudy and moonless nights. Our study provides novel findings about the behavioural plasticity of guiña in different ambient conditions, and the relative advantage to each colour morph to persist in an increasingly human-dominated landscape.
\end{abstract}

KEYwoRDs: Behavioural patterns, phenotypes, Leopardus guigna

\section{RESUMEN}

Entregamos el primer análisis de patrones de actividad exhibidos por morfos moteados y melánicos de la vulnerable güiña Leopardus guigna, en un paisaje de bosque del sur de Chile. Cámaras trampas mostraron que las güiñas estuvieron mayoritariamente activas en la noche ( $64 \%$ de fotos). Las güiñas melánicas fueron más nocturnas ( $82 \%$ de fotos) que las moteadas más comunes $(57 \%)$. Las güiñas moteadas estuvieron más activas en noches nubosas y oscuras. Nuestro estudio provee nuevos resultados sobre la plasticidad conductual de la guiña en diferentes condiciones ambientales, y la ventaja relativa de cada morfo para persistir en un paisaje cada vez más dominado por el ser humano.

Palabras Claves: Patrones conductuales, fenotipos, Leopardus guigna

Activity patterns in animals are linked to endogenous biological rhythms that track environmental variables (e.g., Kolowski et al. 2007). Environmental factors interact with the appearance of some morphological traits such as body colouration, particularly in mammals (e.g., Caro 2005). Understanding the interplay among environmental factors and behavioural/morphological features may reveal the mechanisms by which some species adapt to, and survive in changing landscapes. Adaptive predatory behaviour patterns have been observed in large (e.g., Panthera tigris, Kawanishi \& Sunquist 2004) and medium-sized (e.g., Leopardus pardalis, Di Bitetti et al. 2006) felids. These patterns support the idea of a temporal synchronization of activity with prey base as well as the association between environmental factors (e.g., ambient light) and hunting efficiency (Penteriani et al. 2013). Considering that 
concealment from prey or predators is a primary function of coat colouration (Caro 2005), a spotted pattern may aid concealment in dappled sunlight conditions, whereas melanism (black coat) probably offers enhanced crypsis in dark, closed habitats (Kitchener et al. 2010). However, the ways in which small wild cats $(<10 \mathrm{~kg})$ exhibit behavioural and morphological adaptations to cope with environmental conditions remain scarcely explored, probably due to the practical limitations to observing cryptic, and often rare, species in their natural environment (Macdonald \& Loveridge 2010).

The guiña, Leopardus guigna is one of the smallest (1.2-2.2 $\mathrm{kg}$ ) felids in the world (Nowell \& Jackson 1996). It is endemic to temperate rainforests of southern Chile and Argentina (30$50^{\circ} \mathrm{S} 70-75^{\circ} \mathrm{W}$, Redford \& Eisenberg 1992). Guiñas occur in both spotted and melanistic coat colour morphs (Sunquist $\&$ Sunquist 2002). They have been described as nocturnal/ crepuscular (Dunstone et al. 2002a; Sanderson et al. 2002; Delibes-Mateos et al. 2014), inhabiting continuous and fragmented forests (Gálvez et al. 2013). However, there is still much unknown about the behavioural and morphological patterns displayed by the species, since only isolated records exist (e.g., Altamirano et al. 2013).

We describe and compare the daily activity patterns displayed by spotted and melanistic guiñas, and the association between moonlight and nocturnal activity of both colour morphs.

The study was conducted in the foothills of the Andes in the Araucanía district of southern Chile. Vegetation cover is primarily deciduous forest dominated by the genus Nothofagus at lower altitudes and deciduous forest mixed with the conifer Araucaria araucana at higher altitudes ( $>$ $900 \mathrm{~m}$ ). The study area covered $1,739 \mathrm{~km}^{2}$ across an elevation gradient ranging from $230 \mathrm{~m}$ a.s.l. in the agricultural valley to $>1200 \mathrm{~m}$ a.s.l.

Between January 2008 and March 2009, we continuously surveyed 27 forest sites. From 2006 to 2010, additional non-continuous surveys were conducted in 100 sites, deploying similar sampling efforts throughout yearly seasons. Surveys were carried out using a combination of analogue (Trailmaster $\left.{ }^{\circledR}\right)$ and digital cameras (Reconyx ${ }^{\circledR}$, Stealthcam $\left.{ }^{\circledR}\right)$. Cameras were placed along trails and tracks $(<20 \mathrm{~cm}$ above ground), programmed to operate 24 hours a day, and visited every 20-25 days. An independent event at a camera site was defined as an image with positive guiña recorded with at least a $1 \mathrm{~h}$ interval from the next detection. Guiña daily activity patterns were described by pooling independent photos from all study sites, assuming that even sampling efforts were deployed through seasons during both continuous and non-continuous surveys. Photo classification accounted for variation on sunrise (i.e., $0800 \mathrm{~h}$ ) and sunset (i.e., $1900 \mathrm{~h}$ ) times, dividing photos into day (0900-1759 h), night (2000-0659 h), dawn (0700-0859 h) and dusk (1800$1959 \mathrm{~h})$. We estimated moon luminosity by calculating a nocturnal illumination index $\left(I_{\text {norm }}(t)\right)$, using moon time duration, moon phase and local cloud cover (Schwitzer et al. 2007). Nonparametric kernel density estimation was used to estimate the probability density function of guiña activity pattern (Linkie \& Ridout 2011). We compared the activity patterns displayed by spotted and melanistic morphs using the overlap coefficient $\Delta_{1}$, which ranges from 0 (no overlap) to 1 (complete overlap). This coefficient has been reported to perform appropriately for small sample sizes (i.e., smaller sample had $<50$ photos of guiña). The precision of $\Delta_{1}$ was determined by the calculation of confidence intervals as percentile intervals from 1,000 bootstrap samples (Linkie \& Ridout 2011). To explore if moon luminosity was differentially associated with the nocturnal activity displayed by both colour morphs, we conducted a two-sample Kolmogorov-Smirnov test and a Wilcoxon ranked sum test. Statistical analyses were carried out with the $\mathrm{R}$ software 2.15.2 (R Development Core Team, 2012), using the package overlap for the kernel density estimation (Meredith \& Ridout 2014). Totalling 11,908 camera-trap days, stations $(n=127)$ recorded 78 independent photos (hereafter photos) of guiñas. The spotted morph (56 photos, $72 \%$ ) was more commonly recorded than the melanistic (22 photos, 28\%). The spotted cats were photographed at more stations than melanistic ones (30 vs. 15 sites). Guiñas were more active during night time, accounting for 50 nocturnal photos (64\%). Eighty two percent of the photos of melanistic guiñas were taken at night, $9 \%$ during the day and $9 \%$ during dawn/dusk. For the spotted cats, $57 \%$ of the photos were taken at night, $25 \%$ during daytime and $18 \%$ during dawn/dusk; thus, records of spotted guiñas were more evenly distributed throughout the $24 \mathrm{~h}$ daily cycle than those of melanistic guiñas, and we observed only a moderate overlap between the activity patterns of the two morphs: $\Delta_{1}=0.68(0.50-0.84)$ (Figure 1a). Nocturnal records of spotted cats mostly coincided with cloudy and darkest nights $\left(75 \%\right.$ of photos associated to $\left.I_{\text {norm }}(t)<1\right)$, whereas those of melanistic cats were more frequent during nights that were brighter (55\% of night melanistic photos occurring with $I_{\text {norm }}(t)>1$ ) (Figure 1b). The Wilcoxon ranked sum test $(\mathrm{W}=820, p=0.024)$ indicated a differential level of moon luminosity over the nocturnal activity displayed by the two guiña colour morphs, and the Kolmogorov-Smirnov test $(\mathrm{D}=$ $0.3785, p=0.054$ ) was also on the borderline of significance.

Our results suggest that guiñas are mostly nocturnal, similarly to other small neotropical felids (e.g., Leopardus geoffroyi, L. colocolo) (Cuéllar et al. 2006; Lucherini et al. 2009), and partially differ with previous studies from radio-collared guiñas in southern localities (i.e., suggesting asymmetrical and nocturnal/crepuscular daily activity 
patterns - Dunstone et al. 2002a; Sanderson et al. 2002). Prior findings have suggested that guiña active behaviour may correspond with peak activity of small mammals (Sanderson et al. 2002), which are the species' main prey items (up to $82 \%$, Dunstone et al. 2002b). Even though the periodicity of activity patterns of small mammals was not assessed during our study, perhaps the mostly nocturnal melanistic guiñas may be taking advantage of their enhanced crypsis during night time, facilitating their hunting on nocturnal rodents (Allen et al. 2011). On the other hand, spotted guiñas may take advantage of their disruptive coat camouflage during daytime as well and, therefore, of the opportunity to prey on day-active prey-items like birds, secondary prey items within guiña's diet (24\%, Dunstone et al. 2002b).

The increased activity of spotted guiñas during cloudy and moonless conditions resembles the negative influence of moonlight on the activity of other felids (e.g., L. pardalis,
P. leo) (Di Bitetti et al. 2006; Packer et al. 2011). Brighter nights may hinder concealment for guiñas. Similarly, small mammals commonly avoid activity during moonlit nights, suggesting a potential degree of synchronization in this predator-prey relationship (e.g., Clarke 1983). A note of caution must be stated regarding the potential role of unmeasured environmental variables on the perception of ambient light by this species (e.g., canopy cover). The higher activity of melanistic cats during moonlit nights (supposed to generate highest contrast in the background) could be confounded by canopy structure patterns in the temperate forests. Probably, dense vegetation cover would impede moonlight from reaching the forest floor, not causing a meaningful effect of luminosity on felid nocturnal behaviour.

Our study provides novel findings about the behavioural patterns showed by guiñas in Chile. Differences in daily and nocturnal activity patterns between spotted and melanistic

a

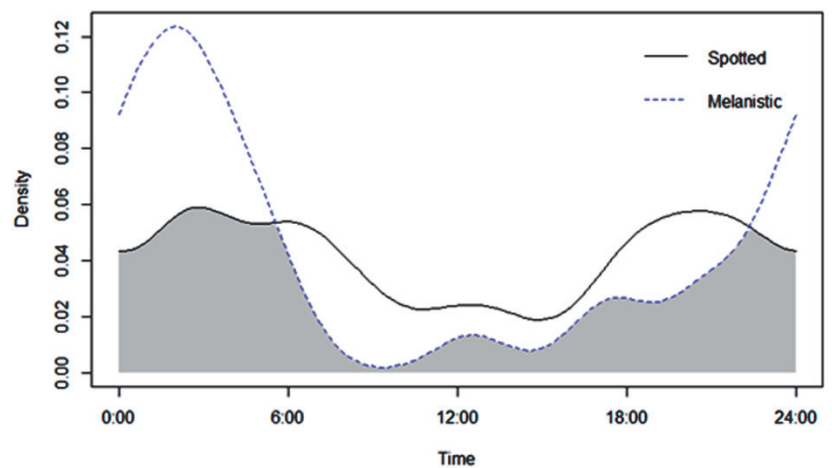

b

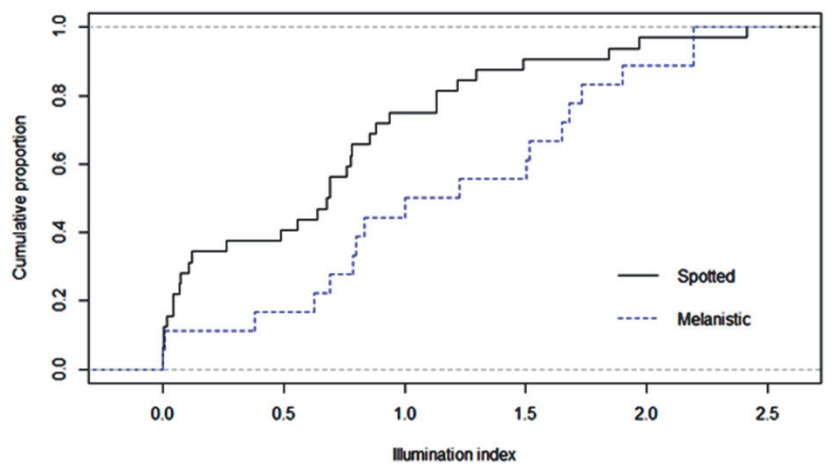

Figure 1 (a) Density estimates of the daily activity patterns of spotted $(\mathrm{n}=56)$ (solid line) and melanistic $(\mathrm{n}=22)($ dashed line) guiñas. Activity overlap between both morphs is represented by the shaded area. Photos were divided into day (0900-1759 h), night (2000-0659 h), dawn (0700-0859 h) and dusk (1800-1959 h); and (b) cumulative proportion of night time photos of spotted (n=32) (solid line) and melanistic $(\mathrm{n}=18)$ (dashed line) guiñas through nocturnal illumination index $\left(I_{\text {norm }}(t)\right)$, recorded by camera traps in the Andean Araucanía of southern Chile

Figura 1 (a) Estimadores de densidad de patrones de actividad diarios de güiñas moteadas $(\mathrm{n}=56)$ (línea sólida) y melánicas $(\mathrm{n}=22)$ (línea discontinua). Traslape de actividad entre ambos morfos es representado por el área sombreada. Clasificación de fotos consideró la variación en tiempos de salida (i.e., 0800 h) y puesta (i.e., 1900 h) del sol, dividiendo las fotos en día (0900-1759 h), noche (2000-0659 h), amanecer (0700-0859 h) y atardecer (1800-1959 h); y (b) proporción acumulada de fotos nocturnas de güiñas moteadas (n=32) (línea sólida) y melánicas $(\mathrm{n}=18)$ (línea discontinua) a través de índice de iluminación nocturna $\left(I_{\text {norm }}(t)\right)$, registradas por cámaras trampa en la Araucanía andina del sur de Chile 
guiñas reflect the behavioural plasticity displayed by both morphs in distinct ambient conditions. They suggest interesting insights about the relative advantage to each colour morph to persist in an increasingly human-dominated landscape, such as the temperate forests of southern Chile.

\section{ACKNOWLEDGEMENTS}

We would like to thank T.A. Altamirano, J.E. Bicknell, A. Boutin, H. Gilabert, A. Hester, J.T. Ibarra, D.W. Macdonald, M. Miranda, T. Murphy, C. Napolitano, O. Ohrens, R. Petitpas, M. Ridout, C. Ríos, J. Sanderson, J. Silva-Lugo, A. Treves, and F. Vidal for valuable support and advice. We thank the forestry and wildlife services (CONAF-SAG) for support in various stages of this work. Field work was funded by a Darwin Initiative project (15/06) and the Ministry of Environment-Chile (FPA 2009-2010). Finally, our deepest appreciation to the many landowners that kindly allowed us to work on their land. FH and NG were supported by CONICYT-Chile.

\section{REFERENCES}

Allen, W.L., Cuthill, I.C., Scott-Samuel, N.E. \& Baddeley, R. 2011. Why the leopard got its spot: relating pattern development to ecology in felids. Proceedings of the Royal Society B 278:1373-1380.

Altamirano, T.A., Hernández, F., de la Maza, M. \& Bonacic, C. 2013. Güiña (Leopardus guigna) preys on cavity-nesting nestlings. Revista Chilena de Historia Natural 86:501-504.

CAro, T. 2005. The Adaptive Significance of Coloration in Mammals. BioScience 55:125-136.

Clarke, J.A. 1983. Moonlight's influence on predator/prey interactions between short-eared owls (Asio flammeus) and deermice (Peromyscus maniculatus). Behavioral Ecology and Sociobiology 13:205-209.

Cuéllar, E., Maffei, L., Arispe, R. \& Noss, A. 2006. Geoffroy's cats at the northern limit of their range: activity patterns and density estimates from camera trapping in Bolivian dry forests. Studies on Neotropical Fauna and Environment 41:169-177.

Delibes-Mateos, M., Díaz-Ruiz, F., Caro, J. \& Ferreras, P. 2014. Activity patterns of the vulnerable guiña (Leopardus guigna) and its main prey in the Valdivian rainforest of southern Chile. Mammalian Biology 79:393-397.

Di Bitetti, M.S., Paviolo, A. \& Angelo, C.D. 2006. Density, habitat use and activity patterns of ocelots (Leopardus pardalis) in the Atlantic Forest of Misiones, Argentina. Journal of Zoology 270:153-163.

Dunstone, N., Durbin, L., Wyllie, I., Freer, R., Acosta, G., Mazzolli, M. \& Rose S. 2002a. Spatial organization, ranging behaviour and habitat use of the kodkod (Oncifelis guigna) in southern Chile. Journal of Zoology 257:1-11.

Dunstone, N., Freer, R., Acosta-Jamett, G., Durbin, L., Wyllie, I.,
Mazzolli, M. \& ScotT, D. 2002b. Uso del hábitat, actividad y dieta de la guiña (Oncifelis guigna) en el Parque Nacional Laguna San Rafael, XI Región, Chile. Boletín del Museo Nacional de Historia Natural (Santiago) 51:147-158.

Gálvez, N., Hernández, F., Laker, J., Gilabert, H., Petitpas, R., Bonacic, C., Gimona, A., Hester, A. \& Macdonald, D.W. 2013. Forest cover outside protected areas plays an important role in the conservation of the Vulnerable guiña Leopardus guigna. Oryx 47:251-258.

Kawanishi, K. \& Sunquist, M.E. 2004. Conservation status of tigers in a primary rainforest of Peninsular Malaysia. Biological Conservation 120:329-344.

Kitchener, A.C., van Valkenburgh, B. \& Yamaguchi, N. 2010. Felid form and function. En: Biology and Conservation of Wild Felids (Eds. Macdonald, D.W. \& A.J. Loveridge), pp. 83-106. Oxford University Press, Oxford.

Kolowski, J.M., Katan, D., Theis, K.R. \& Holekamp, K.E. 2007. Daily patterns of activity in the spotted hyena. Journal of Mammalogy 88:1017-1028.

Linkie, M. \& Ridout, M.S. 2011. Assessing tiger-prey interactions in Sumatran rainforests. Journal of Zoology 284:224-229.

Lucherini, M., Reppucci, J.I., Walker, R.S., Villalba, M.L., Wurstten, A., Gallardo, G., Iriarte, A., Villalobos, R. \& Perovic, P. 2009. Activity Pattern Segregation of Carnivores in the High Andes. Journal of Mammalogy 90:1404-1409.

Macdonald, D.W. \& Loveridge, A.J. 2010. Dramatis personae: an introduction to the wild felids. En: Biology and Conservation of Wild Felids (Eds. Macdonald, D.W. \& A.J. Loveridge), pp. 3-58. Oxford University Press, Oxford.

Meredith, M. \& Ridout, M.S. 2014. overlap: Estimates of coefficient of overlapping for animal activity pattern. $\mathrm{R}$ package version 0.2.4 http://cran.r-project.org/web/ packages/overlap/index.html

Nowell, K. \& JACKSON, P. 1996. Wild cats: status survey and conservation action plan. IUCN/SSC Cat Specialist Group, Gland. 383 pp.

Packer, C., Swanson, A., Ikanda, D. \& Kushnir, H. 2011. Fear of Darkness, the Full Moon and the Nocturnal Ecology of African Lions. PloS One 6(7):e22285.

Penteriani, V., Kuparinen, A., Delgado, M.D.M., Palomares, F., López-Bao, J.V., Fedriani, J.M., Calzada, J., Moreno, S., Villafuerte, R., Campioni, L. \& Lourenço, R. 2013. Responses of a top and meso predator and their prey to moon phases. Oecologia 173:753-766.

Redford, K.H. \& EisenberG, J.F. 1992. Mammals of the Neotropics: the southern cone: 2 , The southern cone: Chile, Argentina, Uruguay, Paraguay. University of Chicago Press. Chicago, IL. 430 pp.

Sanderson, J., Sunquist, M.E. \& Iriarte, J.A. 2002. Natural history and landscape-use of guignas (Oncifelis guigna) on Isla Grande de Chiloé, Chile. Journal of Mammalogy 83:608-613.

Schwitzer, N., Kaumanns, W., Seitz, P.C. \& Schwitzer, C. 2007. Cathemeral activity patterns of the blue-eyed black lemur Eulemur macaco flavifrons in intact and degraded forest fragments. Endangered Species Research 3:239-247.

Sunquist, M.E. \& Sunquist, F. 2002. Wild Cats of the World. University of Chicago Press. Chicago, IL. 462 pp.

Recibido: 17.06 .14

Aceptado: 18.01 .15 